\title{
Association Between County-Level Racial and Ethnic Characteristics and COVID-19 Cases and Deaths in the USA
}

J Gen Intern Med 35(10):3126-8

DOI: $10.1007 / \mathrm{s} 11606-020-06083-8$

(C) Society of General Internal Medicine 2020

\section{INTRODUCTION}

Coronavirus disease 2019 (COVID-19) has resulted in over 1.5 million infections and 100,000 deaths in the USA. Early reports indicated that communities with high proportions of racial and ethnic minorities may be disproportionately affected. However, existing evidence is limited to studies that examined simple correlations without adjustments for potential confounders ${ }^{1}$ or compared counties in a single state (Massachusetts). ${ }^{2}$ Another recent study sought to answer this question by using national county-level data, but compared counties with disproportionately high numbers of Black residents-which are predominantly (91\%) located in the South-versus counties with a lower proportion of Black residents across states. Therefore, the study effectively compared the South versus other regions of the USA. ${ }^{3}$ More importantly, states vary substantially in their responses to the COVID-19 pandemic; therefore, not accounting for state characteristics may lead to biased estimates of the relationship between the proportion of Black residents and the impact of COVID-19 outbreaks.

\section{METHODS}

The exposure variables included county-level percent Black, percent Hispanic, median household income, percent poverty, and percent unemployment (the 2018 American Community Survey [ACS] and the February 2020 Bureau of Labor Statistics unemployment report).

The outcome variables included county-level COVID-19 cases and deaths per 100,000 population (Center for Systems Science and Engineering [CSSE] at Johns Hopkins University [JHU]). We limited our analysis to the 50 states and the District of Columbia from January 22 through May 31, 2020.

Received June 8, 2020

Accepted July 27, 2020

Published online August 5, 2020
Adjustment variables included county-level percent female, 65+ years, uninsured, and mean household size (2018 ACS); urbanicity (National Center for Health Statistics 2013 Urban-Rural Classification Scheme); air quality and health outcome quartile (a composite measure of the length and quality of life, comparing counties within states $^{4}$ ) (2020 Robert Wood Johnson Foundation County Health Rankings and Roadmaps); total physicians and hospital beds per capita (2018-2019 Area Health Resources Files from the Health Resources and Services Administration); the existence of a stay-at-home policy (New York Times database ${ }^{5}$ ); and the number of days from the first county-reported COVID-19 case (JHU CSSE). We adjusted for state fixed effects, which control for unobserved factors that vary by state (effectively comparing counties within states).

We first created maps illustrating the geographic distribution of race/ethnicity and COVID-19 cases and deaths. We then examined adjusted associations between the proportion of racial and ethnic minorities and COVID-19 cases and deaths, using multivariable negative binomial regression models. To account for multiple comparisons, we considered $P<0.01$ to be statistically significant.

All analyses were conducted using Stata/SE 16.0. This study was exempted from review by the UCLA Institutional Review Board.

\section{RESULTS}

As of May 31, there were a total of 1,771,243 COVID-19 cases and 102,958 deaths in the 3,142 counties or countyequivalents in the USA. The median (IQR) number of cases was 133.0 (52.7-335.1), and the median (IQR) number of deaths was $2.2(0.0-11.5)$ per 100,000 population. Geographic variation in the burden of COVID-19 overlapped with areas of greater percent minority populations (Fig. 1).

After adjusting for potential confounders, we found that counties with a higher proportion of Black residents had a larger number of cases $(+2.8 \%$ for a 1-point increase in percent population; $95 \% \mathrm{CI},+2.1$ to $+3.6 \% ; P<0.001)$ and deaths $(+2.9 \%$; $95 \% \mathrm{CI},+2.0$ to $+3.8 \% ; P<0.001)$ within states (Table 1). We found no evidence that the proportion of Hispanic residents was associated with the number of COVID19 cases or deaths. 

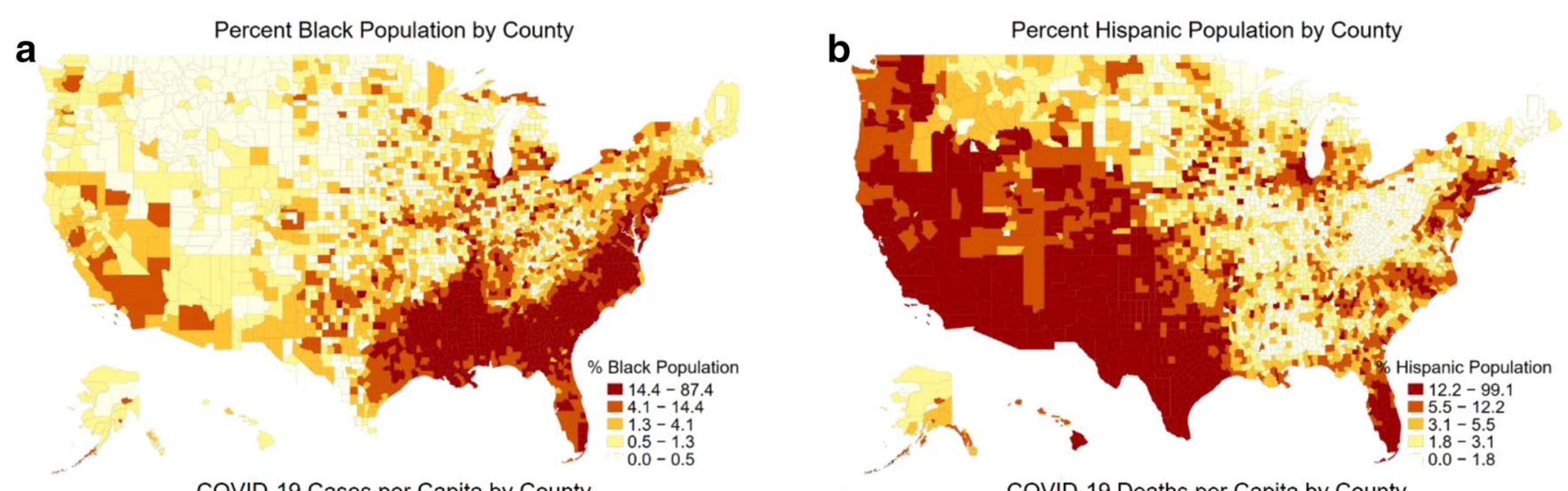

C

COVID-19 Cases per Capita by County
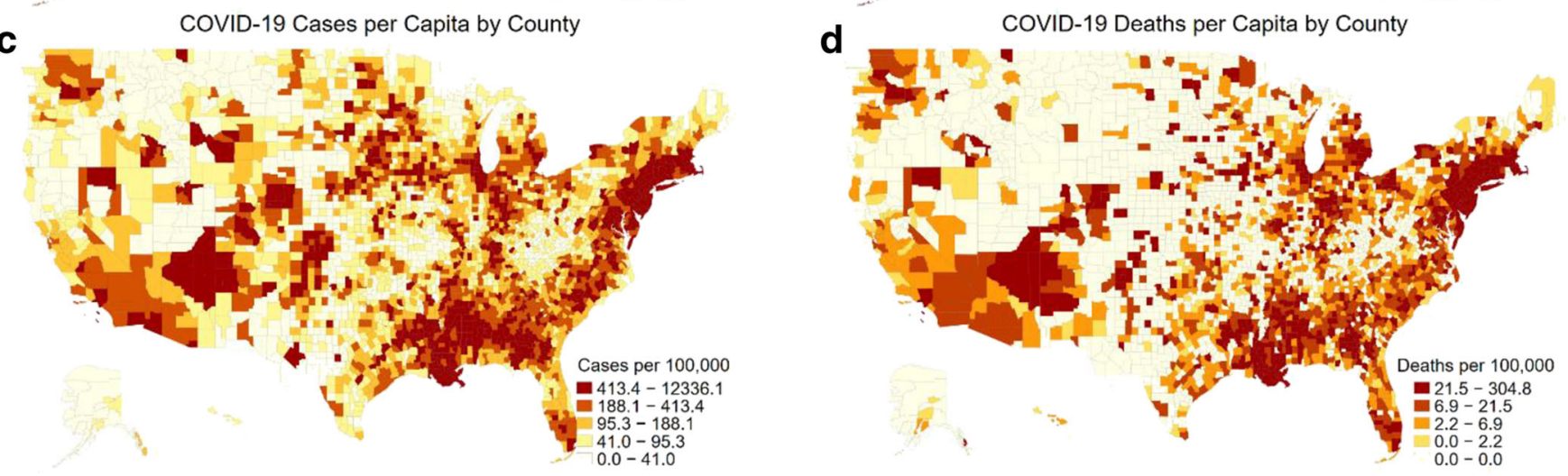

Figure 1 County-level distribution of percent Black population (a), percent Hispanic population (b), COVID-19 cases per capita (c), and COVID-19 deaths per capita (d). The maps are color-coded to show increasing levels of each characteristic by quintile going from lighter to darker shading.

\section{DISCUSSION}

Using national data, we found that counties with a higher percentage of Black residents are experiencing more COVID-19 cases and deaths. Possible reasons for these disparities include geographic concentration of environmental or occupational hazards, inadequate access to high-quality medical care, and racial biases in COVID-19 testing and treatment. These factors are cumulative and have likely contributed to the delayed and more severe presentation of Black patients observed in other studies. ${ }^{6}$
These findings highlight the need for multifaceted policy solutions, such as increased funding of the social safety net, to ensure the COVID-19 pandemic does not further exacerbate racial disparities. Robust data collection is also warranted to guide appropriate resource allocations to vulnerable communities.

Limitations of our study include the possibility of unmeasured confounding, and the use of county-level data precluded us from making inferences about individuallevel relationships between race/ethnicity and the burden of COVID-19 disease.

Table 1 Adjusted Association Between Predictor and Adjustment Variables and COVID-19 Cases and Death per Capita

\begin{tabular}{llll}
\hline \hline & $\begin{array}{l}\text { Percent change in cases } \\
\text { per capita (95\% CI) }\end{array}$ & P value & $\begin{array}{l}\text { Percent change in } \\
\text { deaths per capita (95\% CI) }\end{array}$ \\
\hline Percent Black & $+2.8 \%(+2.1$ to $+3.6 \%)$ & $<0.001$ & $+2.9 \%(+2.0$ to $+3.8 \%)$ \\
Percent Hispanic & $+2.2 \%(-0.3$ to $+4.7 \%)$ & 0.09 & $+1.0 \%(-0.7$ to $+2.7 \%)$ \\
Median household income $(\$ 1000$ units) & $+0.3 \%(-0.7$ to $+1.4 \%)$ & 0.56 & $+1.4 \%(+0.0$ to $+2.7 \%)$ \\
Percent poverty & $+0.3 \%(-1.4$ to $+2.1 \%)$ & 0.71 & $+1.9 \%(-0.6$ to $+4.5 \%)$ \\
Percent unemployment & $-8.5 \%(-11.9$ to $-5.0 \%)$ & $<0.001$ & $-5.5 \%(-14.4$ to $+4.4 \%)$ \\
\hline
\end{tabular}

Adjusted for county-level percent female, 65+ years, uninsured, mean household size, urbanicity, air quality, health outcome quartile (to account for underlying health status), total physicians and hospital beds per capita, presence of a stay-at-home policy, number of days from the first county-reported COVID-19 case, and state fixed effects

$P<0.01$ was considered to be statistically significant to account for multiple comparisons 
Christopher A. Scannell, $M D, P h D^{1,2}$

Carlos Irwin Oronce, $\mathrm{MD}, \mathrm{MPH}^{1,2}$

Yusuke Tsugawa, $\mathrm{MD}, \mathrm{Ph} \mathrm{D}^{2,3}$

${ }^{1}$ VA Greater Los Angeles Healthcare System and the National Clinician Scholars Program,

Los Angeles, CA, USA

${ }^{2}$ Division of General Internal Medicine and Health Services Research, David Geffen School of Medicine at UCLA,

Los Angeles, CA, USA

${ }^{3}$ Department of Health Policy and Management, UCLA Fielding School of Public Health,

Los Angeles, CA, USA

Corresponding Author: Christopher A. Scannell, MD, PhD; Division of General Internal Medicine and Health Services Research, David Geffen School of Medicine at UCLA, Los Angeles, CA, USA (e-mail: cscsannell@mednet.ucla.edu).

Funding Information Drs. Scannell and Oronce are supported by the National Clinician Scholars Program at the University of California, Los Angeles, and by the VA Office of Academic Affiliations through the VA/National Clinician Scholars Program.

\section{Compliance with Ethical Standards:}

This study was exempted from review by the UCLA Institutional Review Board.
Disclaimer: The contents do not represent the views of the US Department of Veterans Affairs or the US Government.

\section{REFERENCES}

1. Mahajan U V, Larkins-Pettigrew M. Racial demographics and COVID-19 confirmed cases and deaths: a correlational analysis of 2886 US counties. J Public Health (Bangkok). 2020:1-4. https://doi.org/10.1093/pubmed/ fdaa070

2. Chen JT, Waterman PD, Krieger N. COVID-19 and the unequal surge in mortality rates in Massachusetts, by city/town and ZIP Code measures of poverty, household crowding, race/ethnicity,and racialized economic segregation. HCPDS Work Pap. 2020;19(2). https://www.hsph.harvard. edu/population-development/research/working-papers/harvard-popcenter-working-paper-series/.

3. Millett GA, Jones AT, Benkeser D, et al. Assessing Differential Impacts of COVID-19 on Black Communities. Ann Epidemiol. 2020. https://doi.org/ 10.1016/j.annepidem.2020.05.003

4. Health Outcomes | Robert Wood Johnson Foundation County Health Rankings \& Roadmaps. https://www.countyhealthrankings.org/explorehealth-rankings/measures-data-sources/county-health-rankings-model/ health-outcomes. Accessed May 20, 2020.

5. Mervosh S, Lu D, Swales V. See Which States and Cities Have Told Residents to Stay at Home. The New York Times. https:// www.nytimes.com/interactive/2020/us/coronavirus-stay-at-homeorder.html. Published April 20, 2020. Accessed April 22, 2020.

6. Price-Haywood EG, Burton J, Fort D, Seoane L. Hospitalization and Mortality among Black Patients and White Patients with Covid-19. N Engl $J$ Med. May 2020. https://doi.org/10.1056/NEJMsa2011686

Publisher's Note Springer Nature remains neutral with regard to jurisdictional claims in published maps and institutional affiliations. 